\title{
Article \\ Investigation on GaN-Based Membrane Photonic Crystal Surface Emitting Lasers
}

\author{
Jingtong Bin, Kerui Feng, Wei Shen, Minjia Meng and Qifa Liu *(i)
}

check for updates

Citation: Bin, J.; Feng, K.; Shen, W.; Meng, M.; Liu, Q. Investigation on GaN-Based Membrane Photonic Crystal Surface Emitting Lasers. Materials 2022, 15, 1479. https:// doi.org/10.3390/ma15041479

Academic Editor: George Kenanakis

Received: 25 January 2022

Accepted: 10 February 2022

Published: 16 February 2022

Publisher's Note: MDPI stays neutral with regard to jurisdictional claims in published maps and institutional affiliations.

Copyright: (C) 2022 by the authors. Licensee MDPI, Basel, Switzerland. This article is an open access article distributed under the terms and conditions of the Creative Commons Attribution (CC BY) license (https:// creativecommons.org/licenses/by/ $4.0 /)$.

\author{
College of Telecommunication and Information Engineering, Nanjing University of Posts and \\ Telecommunications, Nanjing 210003, China; b19011829@njupt.edu.cn (J.B.); b19011713@njupt.edu.cn (K.F.); \\ 1220013535@njupt.edu.cn (W.S.); 1221013807@njupt.edu.cn (M.M.) \\ * Correspondence: liuqf@njupt.edu.cn
}

\begin{abstract}
A GaN-based blue photonic crystal surface emitting laser (PCSEL) featured with membrane configuration was proposed and theoretically investigated. The membrane dimension, photonic crystal (PhC) material, lattice constant and thickness were studied by RCWA (Rigorous Coupled Wave Analysis), FDTD (Finite Difference Time Domain) simulations with the confinement factor and gain threshold as indicators. The membrane PCSEL's confinement factor of active media is of $13 \sim 14 \%$ which is attributed to multi-pairs of quantum wells and efficient confinement of the mode in the membrane cavity with air claddings. The excellent confinement factor and larger $\mathrm{Q}$ factor of resonance mutually contribute to the lower gain threshold of the design (below $400 \mathrm{~cm}^{-1}$ for GaN-PhC with $100 \mathrm{~nm}$ thick top and bottom GaN layer, $40 \mathrm{~nm}$ hole radius and $40 \mathrm{~nm}$ depth). The $\mathrm{PhC}$ confinement factor exceeds $13 \%$ and $6 \%$ for $\mathrm{TiO}_{2}-\mathrm{PhC}$ with $80 \mathrm{~nm}$ and $60 \mathrm{~nm}$ PhC thickness and $20 \mathrm{~nm}$ and $40 \mathrm{~nm}$ distance between $\mathrm{PhC}$ and active media, respectively. It is around two times larger than that of $\mathrm{GaN}-\mathrm{PhC}$, which is attributed to the higher refractive index of $\mathrm{TiO}_{2}$ that pulls field distribution to the $\mathrm{PhC}$ layer.
\end{abstract}

Keywords: GaN-based PCSELs; membrane configuration; confinement factor; gain threshold; field distribution

\section{Introduction}

Currently, GaN-based blue lasers play a critical role in optical communications, especially underwater communication $[1,2]$. Besides, based on the outstanding properties of GaN laser diodes [3-6], they have been widely used in high-density data storage, laser display, material processing and biomedical devices.

The first semiconductor photonic crystal surface emitting laser (PCSEL) was realized in an InP-based system in 1999 [7]. GaN-based both optically and electrically pumped PCSELs were demonstrated initially in 2008 [8,9]. PCSELs are candidates to operate as a high-power source with a single mode and narrow divergence angle lasing over a broad area [10-15]. Compared with vertical cavity surface-emitting lasers (VCSELs), it does not need the highly reflective Bragg mirror, which is very difficult to implement in a GaN-based material system [16].

Photonic crystals (PhCs) are an excellent structure to form cavities with ultra-high Q-factors and ultra-small mode volumes denoted as high $\mathrm{Q} / \mathrm{V}_{\mathrm{m}}$, which are widely reported [17-20]. These are PhC defect mode cavities with a small cavity region by using surrounding PhCs as the reflector. Lasers based on such nanocavities can achieve strong Purcell effect and low-gain threshold, but a finite output power and difficult electricalpump configuration. PCSELs utilize the multidirectional distributed feedback (DFB) effect of two-dimensional perfect PhCs. The DFB induces in-plane coupling and diffract perpendicularly by the first-order Bragg diffraction of PhCs. In PCSELs, the mode coupling in PhCs and gain media are both critical, where the one provides mode oscillating and extracts light vertically, the other achieves oscillation gain. 
In GaN-based PCSELs, PhCs formed by etching through the gain media are the most commonly reported method $[10,21-23]$ because they can obtain high coupling strength both in PhCs and gain media. However, it damages the active material, which affects the quantum wells' luminescence and the uniform distribution of the injection current. This is the reason why these kinds of structures are always suitable to be optically pumped. Moreover, the dry-etch through quantum wells introduces defects that ultimately reduce the IQE of the device [24]. On the other hand, in order to realize high field coupling in PhCs and quantum wells, all reported GaN-based PCSELs have to employ a relatively thick AlGaN cladding layer to form a waveguide-like structure. The p-doped AlGaN has extremely low electrical conductivity, which results in high operating energy costs $[25,26]$. Despite the use of a thick AlGaN cladding layer, confinement factors in PhCs and the active region of reported electrically pumped GaN-PCSELs are still in a low value range [8,27].

In this work, GaN membrane blue PCSEL is theoretically designed based on a particular fabrication process and material platform. A GaN membrane embedded with multi-quantum wells (MQWs) featuring controllable thickness by III-V; compound dry etching can be realized. The membrane forms a waveguide-like structure with air as the top and bottom claddings. This design avoids the necessity of an AlGaN layer and possesses high coupling strength in PhCs and MQWs because the high refractive index contrast between GaN and air can confine fundamental modes efficiently. Based on this air cladding cavity, the confinement factors (coupling strength) in PhCs and MQWs are considerable, which makes it feasible to use shallow-etched surface PhCs. Compared with the structure of buried PhCs inside the GaN layer [8,27], the PhCs etched on the GaN top surface are easier to fabricate. The regrowth step in buried PhC fabrication has to put the device back into the growth chamber after etching, suffering from poor interfaces and bringing high interface recombination [28]. This kind of non-radiative recombination will damage the laser properties. Besides, the surface PhCs' design is more flexible and optimistic to obtain high coupling strength, especially in PhCs, thus realizing good performance of the laser. Here, we fully explore the PhCs and membrane parameters, optimize the confinement factors and gain threshold by tailoring the fundamental guided modes in the membrane. Square lattice PhCs based on $\mathrm{GaN}$ and $\mathrm{TiO}_{2}$ are investigated and compared.

\section{Materials and Methods}

The schematic of the proposed design and fabrication process is shown in Figure 1. The laser structure is composed of square lattice $\mathrm{TiO}_{2}$ or $\mathrm{GaN}$ PhC layer with thickness $t$, lattice constant $a$, hole radius $r$, under PhC GaN layer with thickness $t_{1}$, bottom GaN layer with thickness $t_{2}, 9$ pairs of InGaN $3 \mathrm{~nm} / \mathrm{GaN} 10 \mathrm{~nm}$ MQWs layer. The fabrication was started with GaN-on-silicon or GaN-on-sapphire wafers, whose structure consists of silicon or sapphire substrate, $1000 \mathrm{~nm}$ AlN and AlGaN buffer layer, and $~ 3000 \mathrm{~nm}$ n-GaN. Two kinds of double-side processes were developed to obtain GaN membrane PCSEL. Route I: First, the wafer with p-contact was bonded with the PDMS stamp; then, the silicon or sapphire substrate was released by dry etching or laser lift-off; finally, GaN thinning, $\mathrm{PhC}$ and n-contact fabrication were performed. Route II: $\mathrm{PhC}$ layer was fabricated first on top of $\mathrm{p}-\mathrm{GaN}$; then $\mathrm{p}$-mesa and $\mathrm{p}, \mathrm{n}$-contact were fabricated; backside substrate releasing and AlN-AlGaN-GaN etching was performed to realize a specific thick membrane cavity. The freestanding GaN-based PCSELs feature mode tuning by GaN-thinning tailoring the guided mode to realize high confinement factors. From a comparison of the electric field distribution of the fundamental guided mode in Figure 1, the high confinement factors in MQWs and PhCs could be obtained in the membrane structure due to the high refractive contrast between $\mathrm{GaN}$ and air. The field distribution and confinement factor were calculated by the Stanford Stratified Structure Solver (S4) based on Rigorous Coupled Wave Analysis (RCWA). S4 is a frequency domain code used to solve layered periodic structures. Internally, it is also called the Fourier Modal Method and the S-matrix algorithm. It allows for fast, accurate prediction of optical propagation through complex 3D structures. A transverse electric (TE) wave was considered in the simulation. 


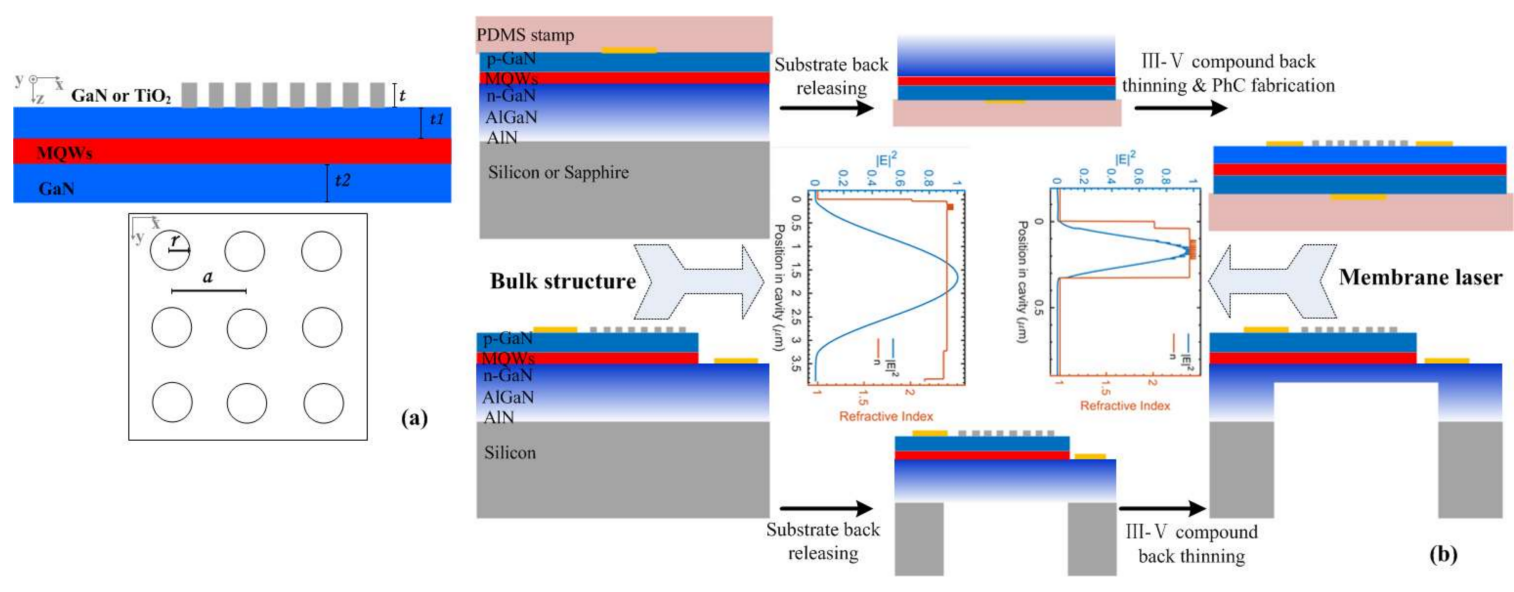

Figure 1. (a) Schematics of the proposed GaN membrane PCSEL structures and (b) the fabrication process. The figure denotes the bulk wafer structure and the calculated fundamental mode distribution with $t_{1}=t_{2}=100 \mathrm{~nm}$.

We performed systematic simulations on structure parameters to investigate the influence on laser properties. The confinement factor in PhCs and gain threshold at resonant wavelengths were calculated and taken as the indicators. The gain threshold was derived from Equation (1):

$$
g_{t h}=\frac{\alpha}{\Gamma_{Q W}}
$$

where $\alpha$ is vertical radiation loss, $\Gamma_{Q W}$ is the field confinement factor in QWs. For large $\mathrm{PhC}$ areas, such as those larger than $400 \mu \mathrm{m}$ in length, the in-plane loss and internal loss can be negligible [12,28-30]. So, only the vertical radiation loss was considered here and calculated by Equation (2):

$$
\alpha=\frac{2 \pi}{Q \cdot a}
$$

where $a$ is the lattice constant and $Q$ is the quality factor obtained by Fano fitting the guided resonances in reflection spectra. The confinement factor in MQWs and PhCs can be calculated by Equation (3):

$$
\Gamma_{Q W}=\frac{\int_{Q W}\left(E_{x}^{2}+E_{y}^{2}\right) \cdot d v}{\int_{c a v}\left(E_{x}^{2}+E_{y}^{2}\right) \cdot d v} \Gamma_{P h C}=\frac{\int_{P h C}\left(E_{x}^{2}+E_{y}^{2}\right) \cdot d v}{\int_{c a v}\left(E_{x}^{2}+E_{y}^{2}\right) \cdot d v}
$$

The confinement factor was calculated by extracting the $E_{x}$ and $E_{y}$ components of the electric field, as the DFB mainly used the oscillation on the PhC surface plane. In S4 simulations, the refractive indexes are set as follows: $n_{\text {air }}=1, n_{\text {silicon }}=4.68, n_{\text {GaN }}=2.4$, $n_{\text {InGaN }}=2.46, n_{A l N}=2.15, n_{A l G a N}=2.354$. The thickness of the substrate and the above air are set to infinite.

\section{Results}

Figure 2 shows the investigation results of $\mathrm{p}-\mathrm{GaN}$ and $\mathrm{n}-\mathrm{GaN}$ thickness $t_{1}$ and $t_{2}$, while the top surface GaN PhC hole depth $t$ is $40 \mathrm{~nm}$, square lattice constant $a$ is $194 \mathrm{~nm}$, and hole radius $r$ is $60 \mathrm{~nm}$. Both the confinement factor and threshold gain decrease as $\mathrm{GaN}$ thickness increases. Top $\mathrm{GaN}$ and bottom $\mathrm{GaN}$ have similar influences on the laser cavity properties. The thinner the top and bottom $\mathrm{GaN}$, the higher the field intensity and the smaller the distance between the active layer and the PhC layer, which produce larger confinement factors. However, the quality factors $(Q$ value) deteriorate along with the membrane thickness, becoming smaller. From Equations (1) and (2), the gain threshold relates to both the $\mathrm{Q}$ value and $\Gamma_{\mathrm{QW}}$. In this case, the $\mathrm{Q}$ factor dominates the influence on $g_{t h}$, thus bringing on larger $g_{t h}$ at smaller membrane thickness. Therefore, for the membrane 
thickness, it is a trade-off to both consider higher PhC coupling strength and lower gain threshold. The membrane thickness should be thin enough to get enough field coupling strength in PhC, which is the necessity of lasing, but should not be too thin to hold a relatively lower threshold.

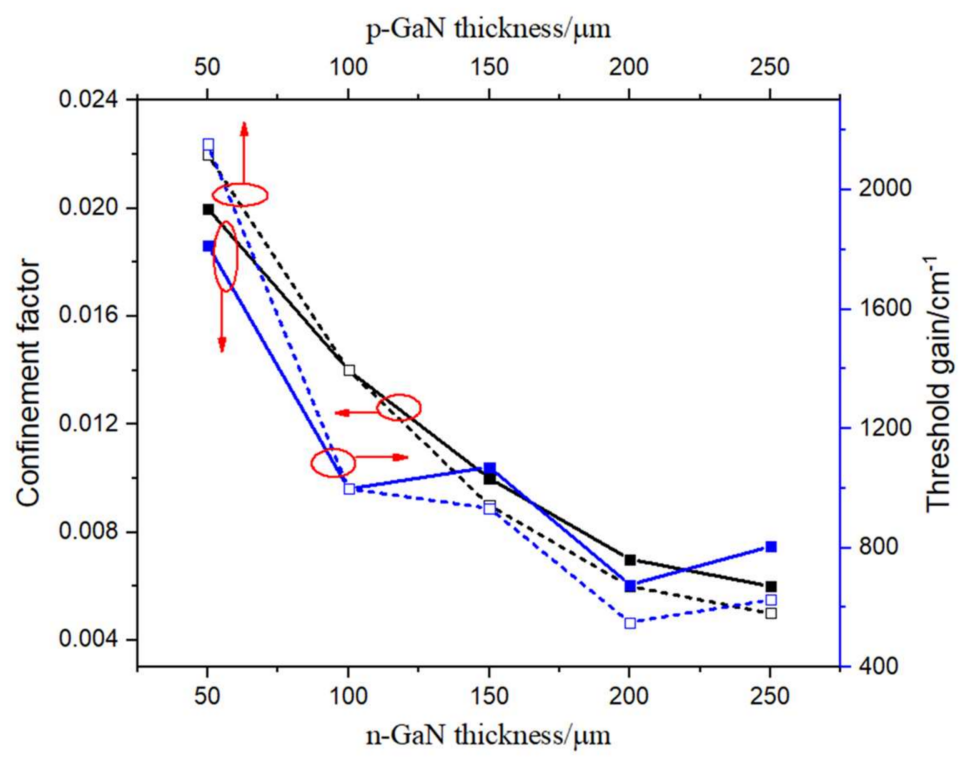

Figure 2. Confinement factor in PhCs and threshold gain plots as functions of $\mathrm{n}-\mathrm{GaN}$ and p-GaN thickness, with holes depth $40 \mathrm{~nm}$, lattice constant $194 \mathrm{~nm}$, and hole radius $60 \mathrm{~nm}$.

Square lattice photonic crystals formed by top GaN partially etched ( $40 \mathrm{~nm}$ depth) with different lattice constants and hole radii were investigated. The $n-G a N$ and p-GaN thicknesses were fixed at $100 \mathrm{~nm}$. The resonant frequency can be tuned by the PhC lattice constant. Considering the luminous band 430 470 nm of the InGaN/GaN MQWs, we designed the lattice constant in the range of 188 to $200 \mathrm{~nm}$. The resonance wavelength is linearly proportioned to the lattice constant with the tune rate of $\lambda_{\text {peak }} /$ lattice constant $=\sim 2.3 \mathrm{~nm} / \mathrm{nm}$. The results are exhibited in Figure 3. At each lattice constant, a $40 \sim 80 \mathrm{~nm}$ hole radius was calculated. We focus on this hole radius range based on the fabrication realizability and the resonance properties. On the one hand, a smaller hole radius is beneficial for a lower gain threshold and larger confinement factors. On the other hand, the fabricated hole radius is still larger than $40 \mathrm{~nm}$ based on the traditional fabrication process. The results in Figure 3 denote that the lattice hole radius has a relatively fine tuning effect on the resonant wavelength. More importantly, the $\mathrm{Q}$ factor of the resonance is dramatically influenced by the hole radius. A smaller hole possesses a sharp reflectance peak, which represents a larger $\mathrm{Q}$ factor. The reflectance curve at a different hole radius of the $194 \mathrm{~nm}$ lattice constant is exhibited as the inset in Figure 3. Therefore, a smaller hole radius can realize less vertical loss, which benefits obtaining a lower threshold gain of the laser. Some of the $Q$ factors are denoted in the figure, from which we can know that the smaller wavelength resonance mode at a smaller lattice constant has slightly higher $Q$ factors.

We also investigated $\mathrm{TiO}_{2}$ as PhCs materials here to give a comparable design for the membrane GaN PCSELs. This reflects the advantage of flexible design for the proposed surface PhCs. $\mathrm{TiO}_{2}$ has negligible absorption at a $\sim 450 \mathrm{~nm}$ wavelength with a 2.55 refractive index [30-32]. This high refractive index will pull field distribution move to PhCs and thus obtain a high $\mathrm{PhC}$ confinement factor. Besides, $\mathrm{TiO}_{2}$ is a widely available material with compatible growth properties and can be easily fabricated as micro-nano structures, such as gratings and photonic crystals [31-35]. 


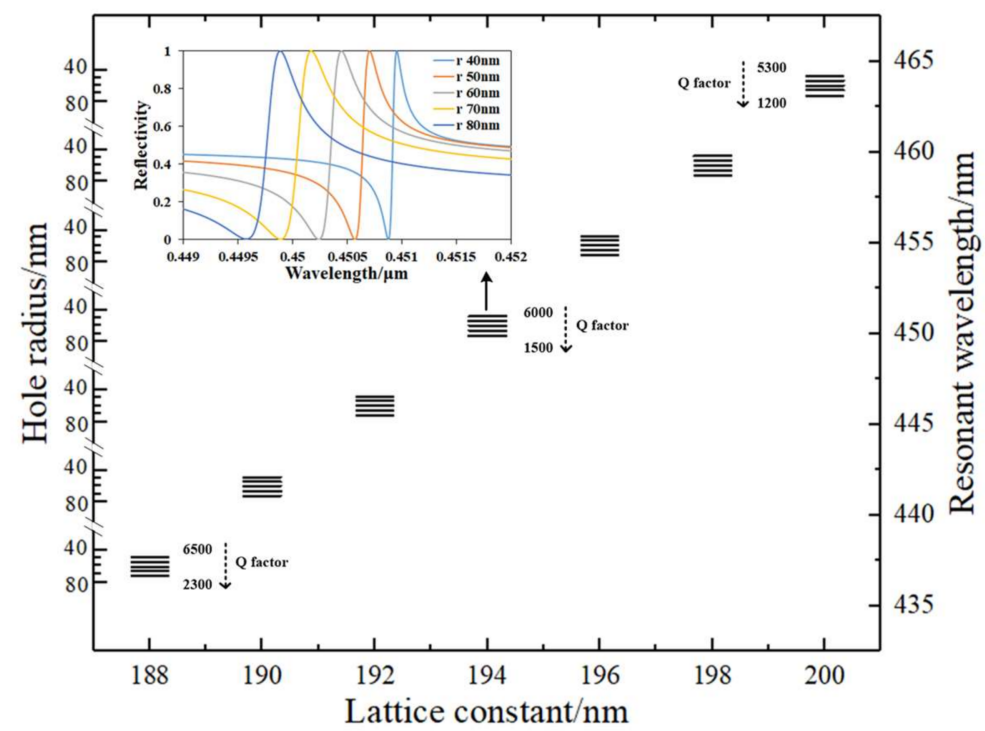

Figure 3. Influence of lattice constant and hole radius on resonant wavelength and mode $Q$ factor.

Different lattice constants and hole radius designs have the function of realizing different wavelength mode lasing, as illustrated in Figure 3. Apparently, every mode has different laser performance as the indicators listed in Table 1. Parameters and performances for $\mathrm{TiO}_{2}-\mathrm{PhC}$ lasers are also listed in Table 1. Other parameters were set the same as GaN$\mathrm{PhC}$, with a $40 \mathrm{~nm}$ PhC layer thickness, $60 \mathrm{~nm}$ GaN layer under PhC and $100 \mathrm{~nm}$ bottom $\mathrm{GaN}$ layer. From the table, smaller holes exert positive effects on both $\mathrm{PhC}$ confinement factors and gain threshold. As shown in Table 1, smaller holes can support resonance with smaller radiation loss, thus reducing the threshold of the laser. We also note that the threshold corresponds to the confinement factor in MQWs from Equation (1). In all of our calculated results, $\Gamma_{Q W}$ are in the range of $13 \sim 14 \%$ at various parameters, which has a finite influence on threshold changes. However, it should be pointed out that the larger $\Gamma_{Q W}$ contributes to the relatively lower gain threshold. The larger $\Gamma_{Q W}$ is due to multi-pairs of quantum wells and the good confinement of the mode in the membrane cavity with air claddings. $\mathrm{TiO}_{2}-\mathrm{PhC}$ has a larger $\mathrm{PhC}$ confinement factor and a higher threshold compared to GaN-PhC. The strong coupling strength is attributed to the high refractive index of $\mathrm{TiO}_{2}$, which pulls the field distribution to the surface. Smaller holes have larger $\mathrm{PhC}$ confinement factors, which is also due to the higher effective refractive index of the PhC layer.

Hole depth (PhC layer thickness) also has obvious influences on PCSELs. Figure 4 exhibits the indicators changing with $\mathrm{PhC}$ hole depth while keeping the distance from active region to top surface at $100 \mathrm{~nm}$, lattice constant at $194 \mathrm{~nm}$ and bottom GaN thickness at $100 \mathrm{~nm}$. The confinement factors and gain threshold both increase as the hole depth increases, no matter what the $\mathrm{PhC}$ material or hole radius is. Along with etching deeper, the distance between $\mathrm{PhC}$ and active region decreases, achieving higher field coupling strength in PhC. However, the radiation loss of the resonant mode increases when holes become deeper, which causes the threshold to increase. The comparison between GaN-PhC and $\mathrm{TiO}_{2}-\mathrm{PhC}$ is clearly shown in Figure 4. PCSELs with $\mathrm{TiO}_{2}-\mathrm{PhC}$ possess a larger $\mathrm{PhC}$ confinement factor and larger threshold gain. The $\mathrm{TiO}_{2}-\mathrm{PhC}$ confinement factor is around two times larger than that of GaN-PhC. The inset shows the field distribution of GaN-PhC and $\mathrm{TiO}_{2}-\mathrm{PhC}$ at a $40 \mathrm{~nm}$ hole radius with $40 \mathrm{~nm}$ and $80 \mathrm{~nm}$ hole depth, respectively. Obviously, in both situations, the fundamental field profile moves to the PhC layer when changing $\mathrm{GaN} \mathrm{PhC}$ to $\mathrm{TiO}_{2} \mathrm{PhC}$. Up to $13 \%$ confinement factor can be achieved with $80 \mathrm{~nm}$ hole depth. 
Table 1. Specific list of $\Gamma_{\mathrm{PhC}}, \mathrm{g}_{\mathrm{th}}$, at different $\mathrm{GaN}-\mathrm{PhC}$ and $\mathrm{TiO}_{2}-\mathrm{PhC}$ parameters $(t=40 \mathrm{~nm}$, $t_{1}=60 \mathrm{~nm}, t_{2}=100 \mathrm{~nm}$. $a$ and $r$ unit in $n m, g_{t h}$ unit in $\left.\mathrm{cm}^{-1}\right)$.

\begin{tabular}{|c|c|c|c|c|c|c|}
\hline \multirow{2}{*}{$\begin{array}{l}\text { Lattice Constant }(a) \\
\text { Hole Radius }(r)\end{array}$} & \multicolumn{3}{|c|}{ GaN-PhC } & \multicolumn{3}{|c|}{$\mathrm{TiO}_{2}-\mathrm{PhC}$} \\
\hline & 188 & 194 & 200 & 188 & 194 & 200 \\
\hline 40 & $\begin{array}{l}\Gamma_{P h C}=2 \% \\
g_{t h}=376\end{array}$ & $\begin{array}{l}\Gamma_{P h C}=2 \% \\
g_{t h}=379\end{array}$ & $\begin{array}{c}\Gamma_{P h C}=2.1 \% \\
g_{t h}=409\end{array}$ & $\begin{array}{l}\Gamma_{P h C}=3 \% \\
g_{t h}=556\end{array}$ & $\begin{array}{c}\Gamma_{P h C}=3.1 \% \\
g_{t h}=516\end{array}$ & $\begin{aligned} \Gamma_{P h C} & =3.1 \% \\
g_{t h} & =571\end{aligned}$ \\
\hline 50 & $\begin{array}{c}\Gamma_{P h C}=1.6 \% \\
g_{t h}=613\end{array}$ & $\begin{array}{c}\Gamma_{P h C}=1.7 \% \\
g_{t h}=653\end{array}$ & $\begin{array}{c}\Gamma_{P h C}=1.7 \% \\
g_{t h}=700\end{array}$ & $\begin{aligned} \Gamma_{P h C} & =2.4 \% \\
g_{t h} & =904\end{aligned}$ & $\begin{array}{c}\Gamma_{P h C}=2.5 \% \\
g_{t h}=922\end{array}$ & $\begin{aligned} \Gamma_{P h C} & =2.6 \% \\
g_{t h} & =945\end{aligned}$ \\
\hline 60 & $\begin{array}{c}\Gamma_{P h C}=1.3 \% \\
g_{t h}=941\end{array}$ & $\begin{array}{c}\Gamma_{P h C}=1.4 \% \\
g_{t h}=998\end{array}$ & $\begin{array}{c}\Gamma_{P h C}=1.4 \% \\
g_{t h}=1113\end{array}$ & $\begin{array}{c}\Gamma_{P h C}=1.8 \% \\
g_{t h}=1347\end{array}$ & $\begin{array}{c}\Gamma_{P h C}=1.9 \% \\
g_{t h}=1365\end{array}$ & $\begin{array}{l}\Gamma_{P h C}=2 \% \\
g_{t h}=1503\end{array}$ \\
\hline 70 & $\begin{array}{l}\Gamma_{P h C}=1 \% \\
g_{t h}=1155\end{array}$ & $\begin{array}{l}\Gamma_{P h C}=1 \% \\
g_{t h}=1339\end{array}$ & $\begin{array}{c}\Gamma_{P h C}=1.1 \% \\
g_{t h}=1475\end{array}$ & $\begin{array}{c}\Gamma_{P h C}=1.2 \% \\
g_{t h}=1661\end{array}$ & $\begin{array}{c}\Gamma_{P h C}=1.4 \% \\
g_{t h}=1846\end{array}$ & $\begin{array}{c}\Gamma_{P h C}=1.5 \% \\
g_{t h}=2055\end{array}$ \\
\hline 80 & $\begin{array}{c}\Gamma_{P h C}=0.7 \% \\
g_{t h}=1046\end{array}$ & $\begin{array}{c}\Gamma_{P h C}=0.8 \% \\
g_{t h}=1429\end{array}$ & $\begin{array}{c}\Gamma_{P h C}=0.9 \% \\
g_{t h}=1707\end{array}$ & $\begin{array}{c}\Gamma_{P h C}=0.9 \% \\
g_{t h}=1541\end{array}$ & $\begin{array}{l}\Gamma_{P h C}=1 \% \\
g_{t h}=1934\end{array}$ & $\begin{array}{c}\Gamma_{P h C}=1.1 \% \\
g_{t h}=2305\end{array}$ \\
\hline
\end{tabular}

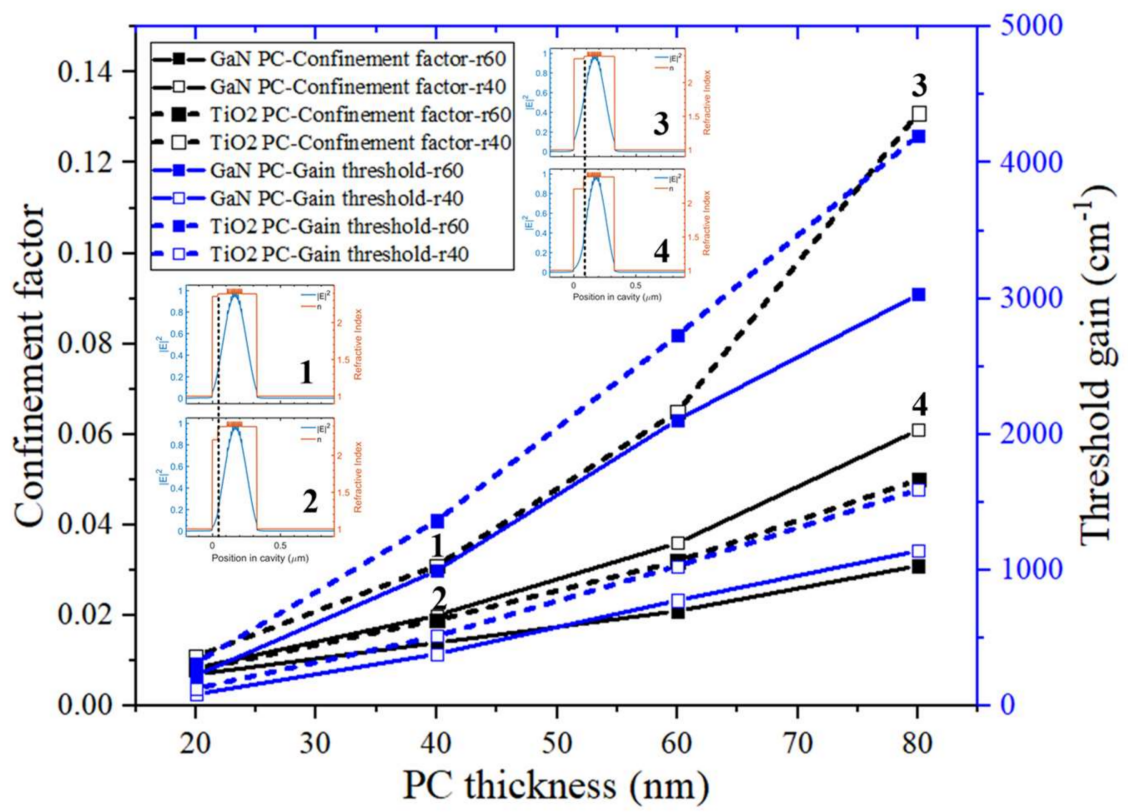

Figure 4. PhC confinement factor and gain threshold changing with PhC layer thickness of GaN-PhC and $\mathrm{TiO}_{2}-\mathrm{PhC}$ at hole radius of $40 \mathrm{~nm}$ and $60 \mathrm{~nm}$, respectively. The insets exhibit mode distribution in layers at $40 \mathrm{~nm}$ hole radius with (1) $40 \mathrm{~nm}$ and (3) $80 \mathrm{~nm} \mathrm{TiO} 2-\mathrm{PhC}$ hole depth and (2) $40 \mathrm{~nm}$ and (4) $80 \mathrm{~nm}$ GaN-PhC hole depth.

The finite difference time domain (FDTD) method was employed to calculate the field distribution. Figure 5a,b exhibit field distribution in the PhC layer and cross-sectional view of the PCSELs with lattice constant $194 \mathrm{~nm}$, hole radius $40 \mathrm{~nm}$, and hole depth $40 \mathrm{~nm}$ of $\mathrm{GaN}-\mathrm{PhC}$ at resonant peaks of $450.95 \mathrm{~nm}$. Figure $5 \mathrm{c}$,d exhibit field distribution in the PhC layer and cross-sectional view of the PCSELs that of $\mathrm{TiO}_{2}-\mathrm{PhC}$ at resonant peaks of $451.67 \mathrm{~nm}$. Resonances of the fundamental mode at these two wavelengths are apparently formed and oscillating confined in the membrane. Both fields have large coupling in MQWs and small coupling in the $\mathrm{PhC}$ layer, and the coupling in $\mathrm{TiO}_{2}-\mathrm{PhC}$ is slightly bigger than that in GaN-PhC. The FDTD simulation results verify the preceding results from RCWA. 

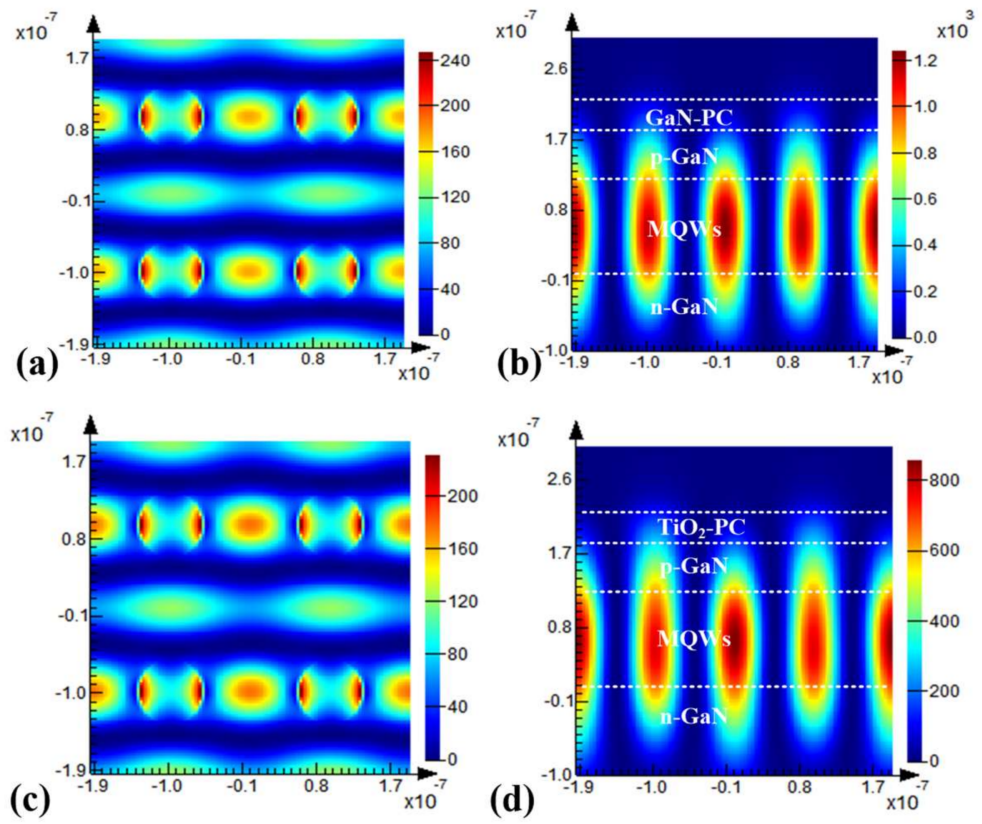

Figure 5. Field distribution in PhC surface plane $(\mathbf{a}, \mathbf{c})$ and cross-section plane $(\mathbf{b}, \mathbf{d})$ of the PCSELs with lattice constant $194 \mathrm{~nm}$, hole radius $40 \mathrm{~nm}$, hole depth $40 \mathrm{~nm}$ of $\mathrm{GaN}-\mathrm{PhC}(\mathbf{a}, \mathbf{b})$ and $\mathrm{TiO}_{2}-\mathrm{PhC}$ (c,d) at resonant peaks of $450.95 \mathrm{~nm}$ and $451.67 \mathrm{~nm}$, respectively.

The photonic band structure of the proposed GaN-PCSELs with top $\mathrm{TiO}_{2} \mathrm{PhC}$ was calculated by MIT photonic bands (MPB), based on the fully vectorial plane wave expansion method (PWE). The general calculation approach can be referred to in many reports [36,37]. A lasing oscillation is considered to occur at the band edges of the $\Gamma$ point, which is denoted in the figure. From Figure 6, the normalized frequency of the band edge in the band structure is around 0.42. Based on this, the calculated lattice constant is around $190 \mathrm{~nm}$. This is in accordance with the designed parameters above, which explains and verifies the design. The GaN membrane PCSEL design based on the band-edge effect has also been verified by photonic band structure calculation in our previous article [38].

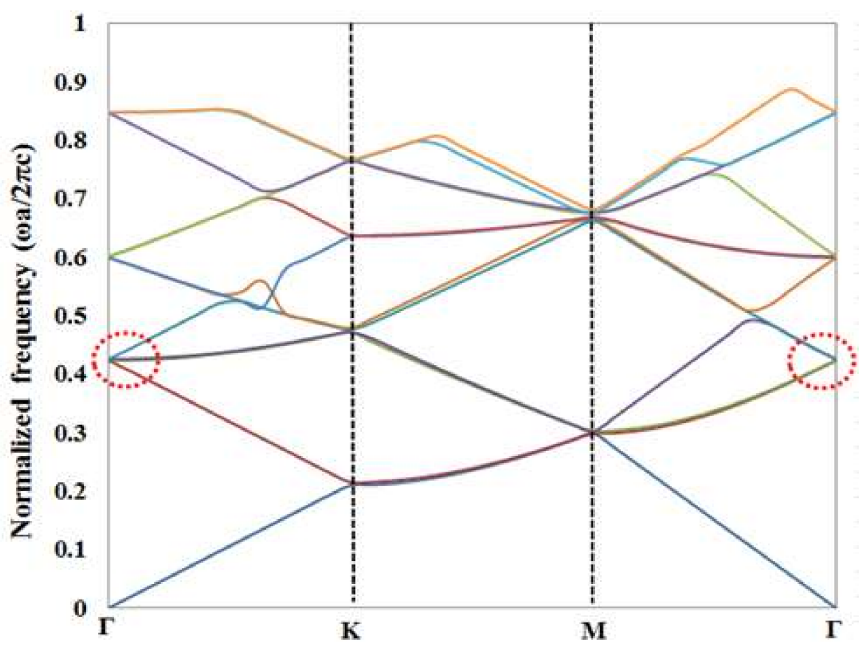

Figure 6. Photonic band structure of the proposed GaN-PCSELs with $\mathrm{TiO}_{2} \mathrm{PhC}$ of TE polarization.

\section{Conclusions}

In this work, a membrane structure was proposed in PCSELs for GaN-based blue lasers. The slab-waveguide-like membrane gives birth to both large confinement factors in PhCs and MQWs, which is a promising candidate to be a distinguished PCSEL cavity. 
Parameters such as membrane thickness, PhC lattice constant, hole radius and depth, as well as different PhC materials were investigated by RCWA simulation to analyze the influence on confinement factors and gain threshold.

The membrane thickness should be thin to get enough field coupling strength in $\mathrm{PhC}$ but should not be too thin to hold a relatively lower threshold. A smaller hole radius is preferred because it features higher coupling strength in PhCs and less vertical loss, which benefits obtaining a lower gain threshold. The lattice constant is linearly proportioned to the resonance wavelength and has a tune rate of $\lambda_{\text {peak }} /$ lattice constant $=\sim 2.3 \mathrm{~nm} / \mathrm{nm}$. The confinement factors and gain threshold both increase with hole depth. $\mathrm{TiO}_{2}-\mathrm{PhC}$ brings a higher $\mathrm{PhC}$ confinement factor and higher threshold compared to $\mathrm{GaN}-\mathrm{PhC}$. The $\mathrm{TiO}_{2}-\mathrm{PhC}$ confinement factor is around two times larger than that of $\mathrm{GaN}-\mathrm{PhC}$. This design and investigation paves the way for near future experimental investigations and realization of GaN-based membrane blue PCSELs.

On the other hand, there are some challenges for the realization and application of these membrane lasers. One is that the membrane configuration may suffer a high thermal resistance problem in application. The other is the efficient current injection, which is a problem for GaN-based PCSELs, especially for the membrane structure. In this work, we proposed two ways to realize the laser in Figure 1 with n-GaN and p-GaN on the top, respectively. The former may suffer from high power absorption in PDMS, while the latter is constricted to low carrier mobility of $\mathrm{p}-\mathrm{GaN}$.

Author Contributions: Investigation, writing—original draft, review and editing, J.B.; investigation, methodology, K.F.; investigation, formal analysis, W.S.; investigation, software, M.M.; conceptualization, writing-review and editing, supervision, Q.L. All authors have read and agreed to the published version of the manuscript.

Funding: This work was supported by the China Scholarship Council (No. 201908320061), Postdoctoral Science Foundation Project of China (No. 2018M640507), Open research fund of the National and Local Joint Engineering Laboratory of RF Integration and Micro-Assembly Technology (No. KFJJ20180202), and Fund Project of Nanjing University of Posts and Telecommunications (No. NY218046). The project was supported by Open Fund of IPOC (BUPT) IPOC2021B03.

Institutional Review Board Statement: Not applicable.

Informed Consent Statement: Not applicable.

Data Availability Statement: Not applicable.

Conflicts of Interest: The authors declare no conflict of interest.

\section{References}

1. Tsonev, D.; Videv, S.; Haas, H. Towards a $100 \mathrm{~Gb} / \mathrm{s}$ visible light wireless access network. Opt. Express 2015, $23,1627-1637$. [CrossRef] [PubMed]

2. Rashidi, A.; Rishinaramangalam, A.K.; Aragon, A.A.; Mishkat-Ul-Masabih, S.; Monavarian, M.; Lee, C.; Denbaars, S.; Feezell, D.F. High-Speed Nonpolar InGaN/GaN Superluminescent Diode With 2.5 GHz Modulation Bandwidth. IEEE Photon-Technol. Lett. 2020, 32, 383-386. [CrossRef]

3. Kang, J.H.; Wenzel, H.; Hoffmann, V.; Freier, E.; Sulmoni, L.; Unger, R.-S.; Einfeldt, S.; Wernicke, T.; Kneissl, M. DFB Laser Diodes Based on GaN Using 10th Order Laterally Coupled Surface Gratings. IEEE Photon-Technol. Lett. 2018, 30, 231-234. [CrossRef]

4. Sun, Y.; Zhou, K.; Feng, M.; Li, Z.; Zhou, Y.; Sun, Q.; Liu, J.; Zhang, L.; Li, D.; Sun, X.; et al. Room-temperature continuous-wave electrically pumped InGaN/GaN quantum well blue laser diode directly grown on Si. Light. Sci. Appl. 2018, 7, 13. [CrossRef] [PubMed]

5. Zhu, G.; He, S.; Li, J.; Yuan, J.; Qin, F.; Li, J.; Li, X.; Wang, Y. GaN micro-chimney cavity laser. Opt. Commun. 2020, $474,126054$. [CrossRef]

6. Taher, M.M.; Al-Yousif, S.; Ahmed, N.M. Atomistic modeling of InGaN/GaN quantum dots-in-nanowire for graded surfaceemitting low-threshold, blue exciton laser. Results Phys. 2021, 20, 103732. [CrossRef]

7. Imada, M.; Noda, S.; Chutinan, A.; Tokuda, T.; Murata, M.; Sasaki, G. Coherent two-dimensional lasing action in surface-emitting laser with triangular-lattice photonic crystal structure. Appl. Phys. Lett. 1999, 75, 316-318. [CrossRef]

8. Matsubara, H.; Yoshimoto, S.; Saito, H.; Jianglin, Y.; Tanaka, Y.; Noda, S. GaN Photonic-Crystal Surface-Emitting Laser at Blue-Violet Wavelengths. Science 2008, 319, 445-447. [CrossRef] [PubMed] 
9. Lu, T.C.; Chen, S.W.; Lin, L.F. GaN-based two-dimensional surface-emitting photonic crystal lasers with AlN/GaN distributed bragg reflector. Appl. Phys. Lett. 2008, 92, 011129. [CrossRef]

10. Wu, T.T.; Chen, C.C.; Lu, T.C. Effects of lattice types on GaN-based photonic crystal surface-emitting lasers. IEEE. J. Sel. Top. Quant. 2015, 21, 1700106.

11. Ogawa, S.; Imada, M.; Yoshimoto, S.; Okano, M.; Noda, S. Control of Light Emission by 3D Photonic Crystals. Science 2004, 305, 227-229. [CrossRef]

12. King, B.C.; Rae, K.J.; McKenzie, A.F.; Boldin, A.; Kim, D.; Gerrard, N.D.; Li, G.; Nishi, K.; Takemasa, K.; Sugawara, M.; et al. Coherent power scaling in photonic crystal surface emitting laser arrays. AIP Adv. 2021, 11, 015017. [CrossRef]

13. Chiu, H.-L.; Hong, K.-B.; Huang, K.-C.; Lu, T.-C. Photonic Crystal Surface Emitting Lasers with Naturally Formed Periodic ITO Structures. ACS Photon. 2019, 6, 684-690. [CrossRef]

14. Reilly, K.J.; Kalapala, A.; Yeom, S.; Addamane, S.J.; Renteria, E.; Zhou, W.; Balakrishnan, G. Epitaxial Regrowth and Hole Shape Engineering for Photonic Crystal Surface Emitting Lasers (PCSELs). J. Cryst. Growth 2020, 535, 125531. [CrossRef]

15. Chen, L.-R.; Hong, K.-B.; Huang, K.-C.; Yen, H.-T.; Lu, T.-C. Improvement of output efficiency of p-face up photonic-crystal surface-emitting lasers. Opt. Express 2021, 29, 11293-11300. [CrossRef]

16. Huang, G.; Lu, T.; Yao, H.; Kuo, H.; Wang, S.; Lin, C.; Chang, L. Crack-free GaN/AlN distributed bragg reflectors incorporated with GaN/AlN superlattices grown by metalogarnic chemical vapor deposition. Appl. Phys. Lett. 2006, 88, 061904. [CrossRef]

17. Painter, O.; Lee, R.K.; Scherer, A.; Yariv, A.; O’Brien, J.D.; Dapkus, P.D.; Kim, I. Two-dimensional photonic band-gap defect mode laser. Science 1999, 284, 1819-1821. [CrossRef] [PubMed]

18. Park, H.-G.; Kim, S.-H.; Kwon, S.-H.; Ju, Y.-G.; Yang, J.-K.; Baek, J.-H.; Kim, S.-B.; Lee, Y.-H. Electrically Driven Single-Cell Photonic Crystal Laser. Science 2004, 305, 1444-1447. [CrossRef] [PubMed]

19. Kassa-Baghdouche, L.; Boumaza, T.; Bouchemat, M. Optimization of Q-factor in nonlinear planar photonic crystal nanocavity incorporating hybrid silicon/polymer material. Phys. Scr. 2015, 90, 65504. [CrossRef]

20. Kassa-Baghdouche, L.; Boumaza, T.; Bouchemat, M. Enhancement of Q-factor in SiN-based planar photonic crystal L3 nanocavity for integrated photonics in the visible-wavelength range. Optik 2015, 126, 3467-3471. [CrossRef]

21. Weng, P.H.; Wu, T.T.; Lu, T.C.; Wang, S.C. Threshold gain analysis in GaN-based photonic crystal surface emitting lasers. Opt. Lett. 2011, 36, 1908-1910. [CrossRef] [PubMed]

22. Lu, T.; Chen, S.W.; Kao, T.T.; Liu, T.W. Characteristics of GaN-based photonic crystal surface emitting lasers. Appl. Phys. Lett. 2008, 93, 111111. [CrossRef]

23. Hong, K.B.; Chen, C.C.; Lu, T.C.; Wang, S.C. Lasing characteristics of GaN-based photonic quasi-crystal surface emitting lasers operated at higher order $\Gamma$ mode. IEEE. J. Sel. Top. Quant. 2015, 21, 4900606.

24. Matioli, E.; Weisbuch, C. Impact of photonic crystals on LED light extraction efficiency: Approaches and limits to vertical structure designs. J. Phys. D Appl. Phys. 2010, 43, 354005. [CrossRef]

25. Piprek, J. Energy efficiency analysis of gallium-nitride-based laser diodes. In Proceedings of the International Conference on Numerical Simulation of Optoelectronic Devices (NUSOD), Ottawa, ON, Canada, 8-12 July 2019; pp. 79-80.

26. Piprek, J. Comparative efficiency analysis of GaN-based light-emitting diodes and laser diodes. Appl. Phys. Lett. 2016, 109, 021104 [CrossRef]

27. Kawashima, S.; Kawashima, T.; Nagatomo, Y.; Hori, Y.; Iwase, H.; Uchida, T.; Hoshino, K.; Numata, A.; Uchida, M. GaN-based surface-emitting laser with two-dimensional photonic crystal acting as distributed-feedback grating and optical cladding. Appl. Phys. Lett. 2010, 97, 251112. [CrossRef]

28. Coldren, L.A.; Corzine, S.W. Theoretical GaN in compressive and tensil strained InGaAs/InGaAsP quantum-wells. Appl. Phys. Lett. 1999, 59, 588-590.

29. Liang, Y.; Peng, C.; Sakai, K.; Iwahashi, S.; Noda, S. Three-dimensional coupled-wave analysis for square-lattice photonic crystal surface emitting lasers with transverse-electric polarization: Finite-size effects. Opt. Express 2012, 20, 15945-15961. [CrossRef]

30. Wang, Z.; Liang, Y.; Meng, B.; Sun, T.T.; Omankuttan, G.; Gini, E.; Beck, M.; Scalari, G. Large area photonic crystal quantum cascade laser with $5 \mathrm{~W}$ surface-emitting power. Opt. Express 2019, 27, 2270. [CrossRef] [PubMed]

31. Hashemi, E.; Bengtsson, J.; Gustavsson, J.S.; Carlsson, S.; Rossbach, G.; Haglund, $\AA$. $\mathrm{TiO}_{2}$ membrane high-contrast grating reflectors for vertical-cavity light-emitters in the visible wavelength regime. J. Vac. Sci. Technol. B Nanotechnol. Microelectron. Mater. Process. Meas. Phenom. 2015, 33, 050603. [CrossRef]

32. Heo, J.; Guo, W.; Bhattacharya, P. Monolithic single GaN nanowire laser with photonic crystal microcavity on silicon. Appl. Phys. Lett. 2011, 98, 021110. [CrossRef]

33. Lee, J.; Park, J.; Lee, M. Nanostructured $\mathrm{TiO}_{2}$ diffraction grating fabricated via imprinting and TiCl4treatment. J. Mater. Chem. C 2014, 2, 981-985. [CrossRef]

34. Kim, S.-S.; Chun, C.; Hong, J.-C.; Kim, D.-Y. Well-ordered $\mathrm{TiO}_{2}$ nanostructures fabricated using surface relief gratings on polymer films. J. Mater. Chem. 2006, 16, 370-375. [CrossRef]

35. Choi, K.; Woo, J.; Joo, Y.; Chun, Y.; Kim, C. Dry etching properties of $\mathrm{TiO}_{2}$ thin films in $\mathrm{O}_{2} /$ CF4/Ar plasma. Vacuum 2013, 92 , 83-85. [CrossRef]

36. Sakai, K.; Miyai, E.; Sakaguchi, T.; Ohnishi, D.; Okano, T.; Noda, S. Lasing band-edge identification for a surface-emitting photonic crystal laser. IEEE J. Sel. Area Commun. 2005, 23, 1335-1340. [CrossRef] 
37. Chen, S.W.; Lu, T.C.; Kao, T.T. Study of GaN-based photonic crystal surface-emitting lasers (PCSELs) with AlN/GaN distributed bragg reflectors. IEEE J. Sel. Top. Quantum Electron. 2009, 15, 885-891. [CrossRef]

38. Liu, Q.F.; Wang, Z.H.; Ma, X.Y.; Wang, J.; Zhou, W.D. Design of GaN-based PCSEL with temperature-insensitive lasing wavelength IEEE. Photon. J. 2021, 13, 1500306. [CrossRef] 